\title{
Recurrent cystic hygroma in adult: A case report
}

\author{
Amar Varshney ${ }^{1}$, Rajesh Gangavatiker ${ }^{2}$ \\ From ${ }^{1}$ WG CDR/Classified SPL Surgery, ${ }^{2}$ GP CAPT/Surgeon and HOD, Department of Surgery, 9 Air Force Hospital, Halwara, Punjab, India
}

\begin{abstract}
Cystic hygroma or cystic lymphangioma is a congenital malformation of the lymphatic system that manifests itself as a soft, benign, and painless mass. It is widely accepted that they arise from the remnants of embryonic lymphatic tissue which retains the potential for proliferation. The majority of cases (80-90\%) are diagnosed under the age of 2 and the condition is rare in adulthood. Recurrent cystic hygroma is a known entity and can result from inadequate excision or specific tumor characteristics. We present a case of recurrent cervical cystic hygroma in a 30-year-old female. The patient had undergone excision earlier for a similar type of swelling. She underwent excision and based on histopathology was diagnosed as recurrent cystic hygroma.
\end{abstract}

Key words: Lymphatic malformation, Neck mass, Recurrent cystic hygroma, Surgical excision

$\mathrm{C}$ ystic hygroma is a benign congenital malformation of the lymphatic system that occurs as a result of sequestration or obstruction of the developing lymphatic vessels [1]. It usually affects children under 2 years of age but is quite rare in adults [2]. Clinical presentation depends on the location, size, and rate of growth of malformation. Diagnosis in adults presents a greater challenge than in children, and the final diagnosis is usually based on postoperative histology. Cystic hygroma can be confused with branchial cleft cyst mucocele, ranula, pediatric teratomas, and other germ cell tumors such as thyroglossal duct cyst and thyroid goiter. There are few reported cases of adult cervicofacial cystic hygroma and the optimum management of these lesions is still a matter of debate $[2,3]$. We report a case of recurrent cystic hygroma in the neck of a 30 -year-old woman, which was totally excised.

\section{CASE REPORT}

A 30-year-old woman presented with a painless large swelling in the left side of her neck for 5 months. The swelling was initially small in size and had progressively increased to 10 times of initial size. There was no history of trauma, recent upper respiratory infections, dysphagia, or difficulty in breathing. According to the patient, she had a similar neck mass around 10 years back which was excised. The swelling was excised and was diagnosed as a lymphatic cyst according to the patient.

\section{Access this article online}

Received - 23 February 2021

Initial Review - 11 March 2021

Accepted - 04 May 2021

DOI: 10.32677/IJCR.2021.v07.i06.007
On examination, the pulse was $82 / \mathrm{min}$ and blood pressure was $124 / 80 \mathrm{mmHg}$. Local examination of the neck revealed a cystic swelling measuring approximately $12 \mathrm{~cm} \times 10 \mathrm{~cm}$, which occupied the left posterior triangle of the neck covering the supraclavicular region (Fig. 1). The swelling extended from sternocleidomastoid muscle anteriorly to trapezius muscle posteriorly and it did not move with deglutition. The mass had a globular surface and illdefined edges. It was soft to firm in consistency and brilliantly transilluminant but was not tender or compressible. There was a well-healed scar of previous surgery over the swelling. No palpable lymph nodes were present on either side. The patient had no neurological or vascular deficit. Other systemic reviews were unremarkable.

Ultrasonography revealed a huge cystic lesion in the left lateral aspect of the neck with septations. Magnetic resonance imaging (MRI) revealed a large well-defined lobulated cystic lesion in the left supraclavicular region. The lesion measured $6.2 \mathrm{~cm} \times 5.0 \mathrm{~cm}$ $\times 7.0 \mathrm{~cm}$ (Fig. 2). The lesion reached till left sternocleidomastoid muscle in the anterior aspect, trapezius muscle in the posterior aspect, and reaching up to the skin in the lateral aspect. There were thin internal septations within the lesion with no obvious solid component or eccentric wall thickening or fat content within the lesion.

The patient was taken up for excision under general anesthesia. During surgery, a horizontal incision was given over the bulge of swelling, subcutaneous fat and platysmal flaps were raised and careful dissection was done to remove the lesion. Hemostasis was achieved with cautery. Wound closure was done by suturing subcutaneous tissue followed by the fascia and skin. The patient was discharged in satisfactory condition.

Correspondence to: Dr. Amar Varshney, Department of Surgery, 9 Air Force Hospital, Halwara, Punjab, India. E-mail: amarvarshney@yahoo.co.in

(C) 2021 Creative Commons Attribution-NonCommercial 4.0 International License (CC BY-NC-ND 4.0). 


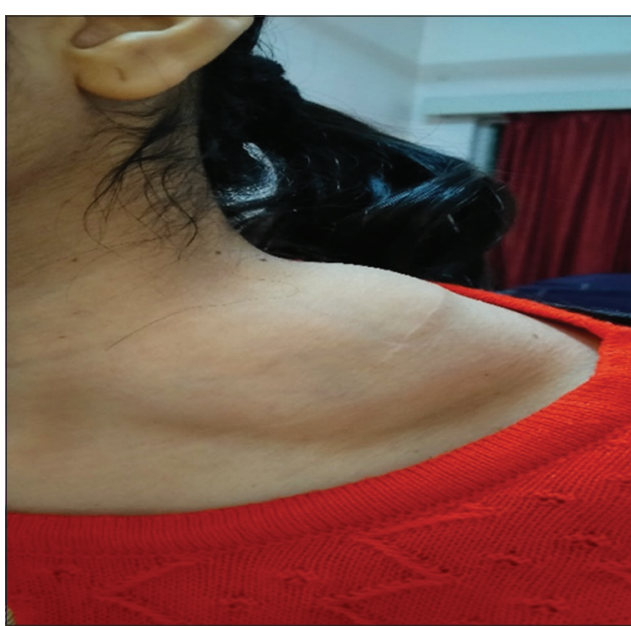

Figure 1: Neck swelling in the posterior triangle with a scar of previous surgery over swelling

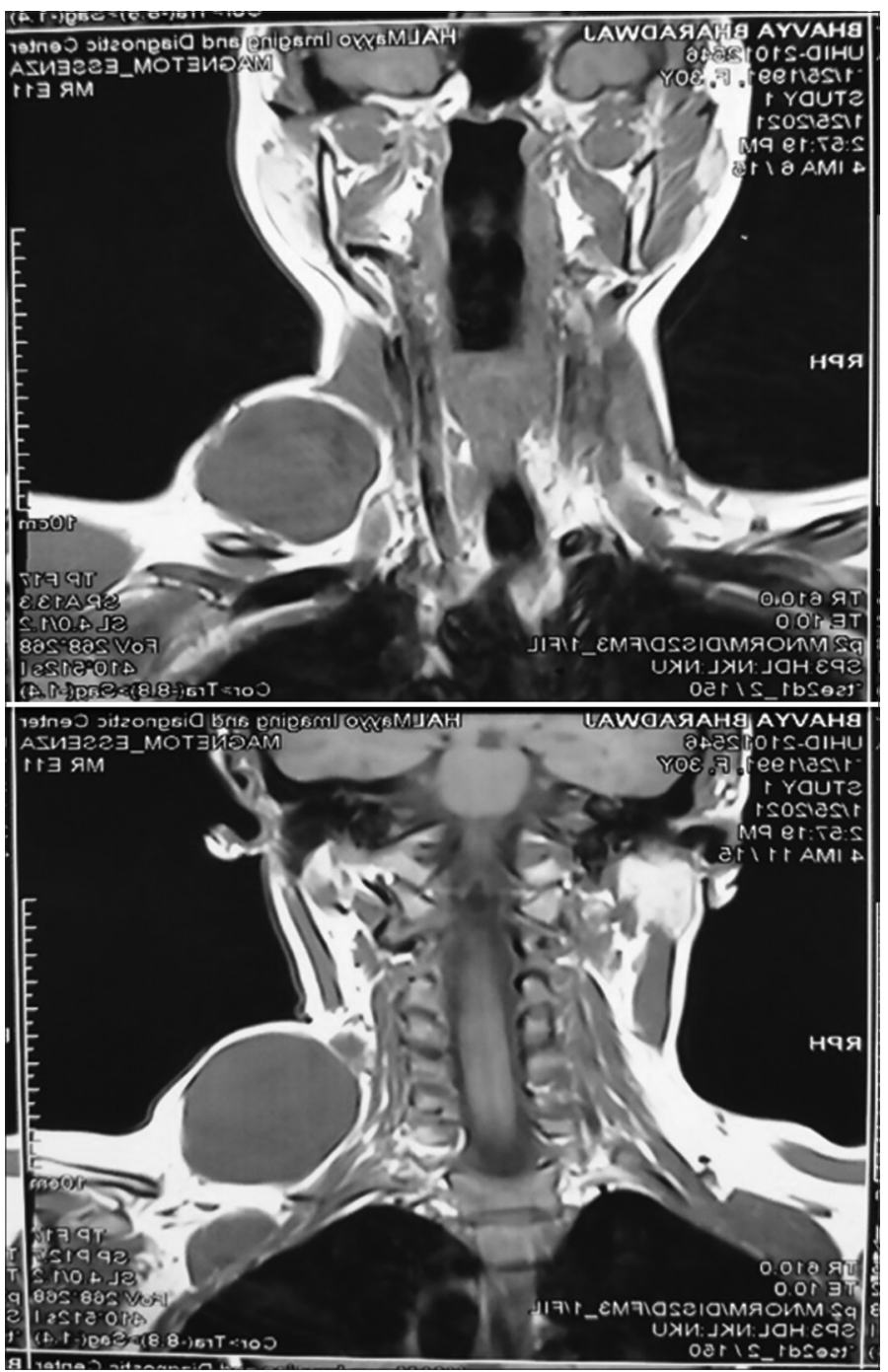

Figure 2: Magnetic resonance imaging revealed a large well-defined lobulated cystic lesion in the left supraclavicular region

The surgical specimen measured $5 \mathrm{~cm} \times 7 \mathrm{~cm}$, appeared irregular in shape but was well-circumscribed. Cut surface revealed multiple cysts like spaces separated by thin fibrous septae and filled with gelatinous material (Fig. 3). Histopathology revealed varying proportions of large and small lymphatic

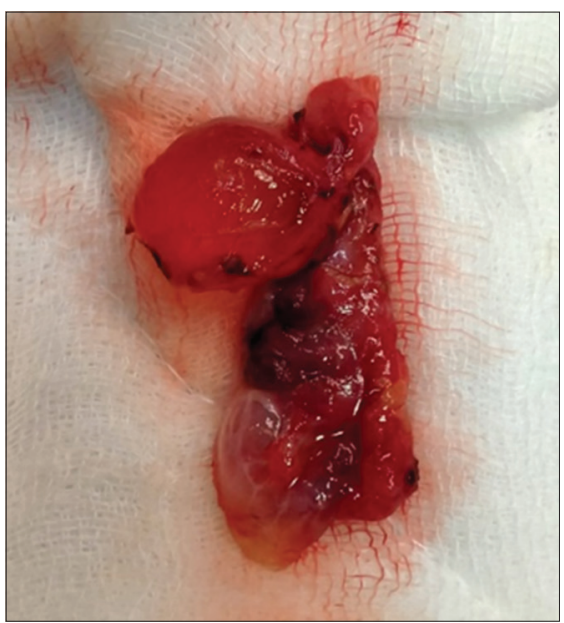

Figure 3: Cut surface revealed multiple cysts like spaces separated by thin fibrous septae and filled with gelatinous material

channels containing lymph, few blood vessels, adipose tissue, fibrous tissue, and lymphoid tissue. Based on the microscopic observations in correlation with clinical features, a final diagnosis of cystic hygroma was made.

\section{DISCUSSION}

Lymphatic malformations are uncommon benign, congenital malformations of the lymphatic system that involves a failure of communication between the lymphatic and the venous pathways which leads to the accumulation of lymph [4]. Cystic hygroma is a misnomer for macrocystic lymphatic malformation. Cystic hygromas are relatively rare lesions. Most cystic hygromas present in utero or in infancy and most of the literature on management considers pediatric cases [5]. However, the etiology for cystic hygroma arising in adults is controversial and it is thought to be an acquired process such as infection, trauma (including surgery), or lymphatic obstruction [6]. The effects of these lesions depend on their locations and relationship with surrounding structures, although the most common adult presentation is of a painless lump in an otherwise asymptomatic patient [7]. Clinical presentation depends on the location, size, and rate of growth of the hygroma. Extensive lesions in the floor of the mouth, oropharynx, or in the neck can lead to pressure manifestations such as dysphagia when compressing the esophagus or dyspnea due to tracheal or laryngeal compression [8].

Various diagnostic modalities have been mentioned in the literature. Imaging methods such as ultrasound, MRI, and computed tomography have been used before treatment [9]. Pre-operative imaging is important to look for intrathoracic extension, which is present in $10 \%$ of cases. In our patient, the diagnosis was made clinically and supported by the ultrasound; we performed MRI for better anatomical mapping and planning for the surgical approach.

Several staging and classification systems have been employed for better diagnosis and management [10]. Kennedy classified these lesions into four types: Superficial cutaneous, cavernous, cystic hygroma, and diffuse systematic [11]. Jackson classified vascular malformations into two types: Low flow and high flow. Lymphatic malformations were classified as low-flow 
lesions. De Serres proposed a staging system according to the location and extent of lesions: Stage 1 is unilateral infrahyoid, Stage 2 is unilateral suprahyoid, Stage 3 is unilateral infrahyoid and suprahyoid, Stage 4 is bilateral infrahyoid, and Stage 5 is bilateral infrahyoid and suprahyoid [12].

Medical therapy using intralesional sclerosants such as ethanol, quinine, bleomycin, and OK-432 has been tried for the treatment of cystic hygroma but their use is limited by the high recurrence rate, rapid increase in the size of the hygroma, inflammation, and alteration of normal tissue planes, and lack of tissue sample for definitive histological diagnosis [13]. Intravenous cyclophosphamide has been used, with some success, in recurrent lesions following surgery [14].

Surgical management is the mainstay of treatment of adultonset cervical cystic hygroma and is based on the principle of meticulous and complete dissection of the cyst from adjacent tissues to prevent a recurrence. We preferred mid-cervical neck incision or over the mass incision because it provided good exposure to the upper-and lowermost part of the cyst, without undue tension, retraction, or compromise of the flaps and could easily be hidden under clothing. Preservation of normal neurovascular structures of the neck is essential. Unlike the congenital variety of cystic hygroma, the adult-type lesions are well defined, making complete surgical excision more feasible [15].

The post-operative complications usually observed after surgical excision of cystic hygroma are wound infection, hemorrhage, hypertrophied scar, and lymphatic discharge from the wound. Complex cystic hygromas recur in about $10-27 \%$ of cases, even after apparent complete excision and $50-100 \%$ in partial excision [16]. Recurrence is due to incomplete excision and is more common with the microcystic and mixed type as they have a tendency to interdigitate into tissue planes, enveloping neural and vascular tissues and complete excision is difficult [16].

Our patient had a similar swelling which was excised 10 years back and she had a recurrence of swelling of only 5 months duration. This is unlikely to be due to incomplete excision and more possibly due to unknown factors such as infection and trauma, leading to lymphatic obstruction. In our patient, we chose the surgical option as she had a recurrent swelling and might present with pressure manifestations subsequently due to the large size of the hygroma. Surgery was straightforward, with complete preservation of vital neck structures, with no post-operative complications, and no recurrence has been reported to date.

\section{CONCLUSION}

Acquired cystic hygroma in adults is a rare condition with variable presentation. The mainstay of treatment is complete excision. Continued reporting of cystic hygroma in adults will help to elucidate various presentations, diagnostic dilemmas, management options, and complications. This case contributes to the specific body of literature on recurrent cystic hygroma in adults.

\section{REFERENCES}

1. Dokania V, Rajguru A, Kaur H, Agarwal K, Kanetkar S, Thakur P, et al. Sudden onset, rapidly expansile, cervical cystic hygroma in an adult: A rare case with unusual presentation and extensive review of the literature. Case Rep Otolaryngol 2017;2017:1061958.

2. Gow L, Gulati R, Khan A, Mihaimeed F. Adult-onset cystic hygroma: A case report and review of management. Grand Rounds 2011;11:5-11.

3. Elshaar K, AbuAleid L. Adult-onset giant cervical cystic hygroma with pressure manifestations on aerodigestive tract, managed surgically: Reporting of a rare case. Ann R Coll Engl 2019;101:84-7.

4. Mirza B, Ijaz L, Saleem M, Sharif M, Sheikh A. Cystic hygroma: An overview. J Cutan Aesthet Surg 2010;3:139-44.

5. Naidu SI, McCalla MR. Lymphatic malformations of the head and neck in adults: A case report and review of the literature. Ann Otol Rhinol Laryngol 2004;113:218-22.

6. Huang YH, Lai YW, Hsieh TY, Lee SS, Chang KP, Lin SD, et al. Axillary cystic hygroma in an adult. Formos J Surg 2014;47:105-7.

7. Copley PC, Ali L, Mirza S. Spontaneous lymphocoele: An unusual cause of an axillary mass. BMJ Case Rep 2016;2016:213088.

8. Bhatia V, Taksande R, Sondankar D. Cystic hygroma in an adult male: A diagnostic challenge. Iran J Pathol 2015;10:310-3.

9. Kumar V, Kumar P, Pandey A, Gupta DK, Shukla RC, Sharma SP, et al. Intralesional bleomycin in lymphangioma: An effective and safe nonoperative modality of treatment. J Cutan Aesthet Surg 2012;5:133-6.

10. Acevedo JL, Shah RK, Brietzke SE. Nonsurgical therapies for lymphangiomas: A systematic review. Otolaryngol Head Neck Surg 2008; 138:418-24.

11. Mehta MR. Cystic hygroma: Presentation of two cases with a review of the literature. Indian J Otolaryngol Head Neck Surg 2000;52:319-22.

12. Hamoir M, Plouin-Gaudon I, Rombaux P, Francois G, Cornu AS, Desuter G, et al. Lymphatic malformations of the head and neck: A retrospective review and a support for staging. Head Neck 2001;23:326-37.

13. de Serres LM, Sie KC, Richardson MA. Lymphatic malformations of the head and neck. A proposal for staging. Arch Otolaryngol Head Neck Surg 1995;121:577-82.

14. Woolley SL, Smith DR, Quine S. Adult cystic hygroma: Successful use of OK-432 (picibanil). J Laryngol Otol 2008;122:1260-4.

15. Rozman Z, Thambidorai RR, Zaleha AM, Zakaria Z, Zulfiqar MA. Lymphangioma: Is intralesional bleomycin sclerotherapy effective? Biomed Imaging Interv J 2011; 7:e18.

16. Kennedy TL, Whitaker M, Pellitteri P, Wood WE. Cystic hygroma/ lymphangioma: A rational approach to management. Laryngoscope 2001;111:1929-37.

Funding: None; Conflicts of Interest: None Stated.

How to cite this article: Varshney A, Gangavatiker R. Recurrent cystic hygroma in adult: A case report. Indian J Child Reports. 2021;7(6):241-243. 